\title{
Clinical and laboratory characteristics of ocular syphilis, co-infection, and therapy response
}

\author{
This article was published in the following Dove Press journal: \\ Clinical Ophthalmology \\ 23 December 2015 \\ Number of times this article has been viewed
}

\author{
Ozlem Sahin' \\ Alireza Ziaei ${ }^{1-3}$ \\ 'Department of Ophthalmology/ \\ Uveitis, Dunya Goz Hospital, \\ Ankara, Turkey; ${ }^{2}$ Department of \\ Ophthalmology, Boston University \\ School of Medicine, Boston, MA, \\ USA; ${ }^{3}$ Department of Ophthalmology, \\ Dunya Eye Hospital Ltd, Ankara, \\ Turkey
}

Purpose: To describe the clinical presentation of patients diagnosed with presumed latent ocular syphilis and congenital ocular syphilis at tertiary referral center in Turkey, and to compare the clinical findings with patients described in other studies, specifically focusing on demographics and co-infections.

Methods: This is a retrospective study reviewing the medical records of patients diagnosed with ocular inflammation between January 2012 and June 2014 at a tertiary referral center in Turkey. Ocular syphilis was diagnosed on the basis of non-treponemal and treponemal antibody tests, and cerebrospinal fluid analysis. All the patients diagnosed with ocular syphilis were tested for human immunodeficiency virus (HIV), Toxoplasma gondii, rubella, cytomegalovirus, and herpes.

Results: A total of 1,115 patients were evaluated between January 2012 and June 2014, and 12 patients $(1.07 \%)$ were diagnosed with ocular syphilis based on the inclusion criteria. None of the patients were seropositive for HIV. Two patients were seropositive for $T$. gondii-specific IgG. Clinical presentations include non-necrotizing anterior scleritis, non-necrotizing sclerokeratitis, anterior uveitis, intermediate uveitis, posterior uveitis, panuveitis, and optic neuritis. All of the patients showed clinical improvement in the level of ocular inflammation with intravenous penicillin 24 million U/day for 10 days. Three patients received additional oral methotrexate as an adjunctive therapy. Two cases received low-dose trimethoprim-sulfamethoxazole.

Conclusion: Ocular syphilis is an uncommon cause of ocular inflammation in HIV-negative patients. Central retinochoroiditis is the most common ocular manifestation, and it is the most common cause of visual impairment. Ocular syphilis might present associated with co-infections such as $T$. gondii in developing countries. Oral methotrexate might be beneficial as an adjunctive therapy for ocular syphilis in resolving the residual intraocular inflammation and cystoid macular edema after specific therapy with intravenous penicillin.

Keywords: ocular syphilis, scleritis, uveitis, methotrexate, human immunodeficiency virus, T. gondii

\section{Introduction}

Syphilis is an infectious disease caused by the spirochete Treponema pallidum which is most often transmitted sexually in acquired disease or vertically during pregnancy in congenital syphilis (CS). ${ }^{1,2}$ Four stages have been described in acquired disease, and overlap can exist between the stages., ${ }^{3,4}$ The primary stage is characterized by a painless ulcerated lesion known as a chancre, which is thought to be the site of entrance into the host. ${ }^{3}$ The secondary stage typically occurs 2 weeks to several months after infection and is associated with a skin rash on the palms of the hands and soles of the feet. ${ }^{4}$ A period of latency can occur after the secondary stage, and recurrences often present during the 1 st year after diagnosis. ${ }^{5}$ Patients can remain in this stage indefinitely or develop tertiary syphilis. ${ }^{5}$
Correspondence: Ozlem Sahin Department of Ophthalmology/Uveitis, Dunya Goz Hospital, Tunus Caddesi No 28 Kavaklıdere, Cankaya, Ankara 06690, Turkey

Tel +903124167000

Email ozlemII58@yahoo.com 
During this stage, serious systemic manifestations occur, including cardiovascular and neurologic symptoms as well as gumma formation throughout the body. ${ }^{6-8}$ Ocular syphilis is considered to occur during any stage of infection, and it is known as "great masquerader". ${ }^{9}$ CS has been classified as early CS and late CS. ${ }^{10}$ Early CS is characterized by organ involvements including liver, kidney, bone, and hematological and mucocutaneous manifestations. ${ }^{10}$ Ocular manifestations including interstitial keratitis, chorioretinitis, salt-pepper fundus, glaucoma, cataract, and chancres of the eyelid have been mostly described in late CS. ${ }^{11}$ Every patient with ocular inflammation is recommended to be tested for syphilis. ${ }^{9}$ Since non-specific treponemal tests, including venereal disease research laboratory test (VDRL) and rapid plasma reagin test (RPR), normalize during the latent and tertiary stages, testing for syphilis should include both non-specific treponemal tests and specific treponemal antibody tests including fluorescent treponemal antibody absorption (FTA-ABS) and the microhemagglutination assay for T. pallidum ${ }^{12}$ (MHA-TP). Treatment for presumed latent ocular syphilis is the same as for neurosyphilis, specifically 10-14 days of intravenous penicillin (IV PCN) 3-4 million units every 4 hours. ${ }^{13}$ In this study, we describe the clinical presentation of patients diagnosed with presumed latent ocular syphilis and congenital late syphilis at a tertiary referral center in Turkey. We compare the clinical findings with patients described in other studies, specifically focusing on demographics and co-infections.

\section{Materials and methods}

This is a retrospective study reviewing the medical records of patients diagnosed with ocular inflammation between January 2012 and June 2014 at a tertiary referral center in Turkey. This study adheres to the tenets of Declaration of Helsinki. Institutional review board/ethics committee approval was obtained from the Dunya Goz Hospital, Ankara Turkey. Written informed consent was obtained for all individuals who enrolled in this study. The results of non-treponemal antibody tests VDRL and RPR, and specific FTA-ABS and MHA-TP, cerebrospinal fluid (CSF) FTA-ABS and CSF protein levels were analyzed. The diagnosis of presumed latent ocular syphilis and presumed congenital late syphilis was done according to the criteria described in the literature. ${ }^{2,13}$ All the patients diagnosed with presumed latent ocular syphilis and presumed congenital late syphilis were tested for human immunodeficiency virus (HIV) and TORCH (Toxoplasma gondii, rubella, cytomegalovirus, herpes). Clinical presentation, demographic information, and response to treatment were collected for each patient. Best corrected visual acuity (BCVA) was tested by using a Snellen chart. Snellen fractions of BCVA were converted to LogMAR. Intraocular pressure was measured by a using non-contact tonometer (NT-530, Nidek Co., Ltd., Gamagori, Japan). Slit-lamp biomicroscopy with SL-D7 (Topcon, Tokyo, Japan) and dilated fundus examination using an indirect ophthalmoscope (Keeler, West Berkshire, UK) were performed for all patients. Fundus fluorescein angiography (FFA), indocyanine green angiography (ICGA), and spectral domain optical coherence tomography (SD-OCT) were done by Spectralis Heidelberg Research Architecture plus optical coherence tomography (HRA + OCT; Heidelberg Engineering, Heidelberg, Germany). Visual field analysis was performed by Humphrey HFA II (Carl Zeiss Meditec AG, Jena, Germany). None of the patients had been treated for syphilis before admission to our clinic. In all, $4(33.3 \%)$ of the 12 patients were receiving oral prednisone less than 3 months duration for their intraocular inflammation at presentation. None of the patients were on topical prednisolone acetate on admission. All of the patients received treatment with IV PCN 24 million U/day for 10 days. IV methylprednisolone for 3 days followed by high-dose oral prednisone was added to IV PCN treatment for the patient with papillitis. Oral methotrexate between 15 and $20 \mathrm{mg} /$ week doses for 6 months was added to three patients 4 weeks after IV PCN therapy. Low-dose trimethoprim-sulfamethoxazole (trimethoprim, $160 \mathrm{mg}$ plus sulfamethoxazole, $800 \mathrm{mg}$; one tablet twice daily, 2 days per week) as primary prophylaxis against $T$. gondii was given for 1 year for 2 patients who were seropositive for specific IgG for T. gondii.

\section{Results}

Medical records of 1,115 patients diagnosed with ocular inflammation were evaluated between January 2012 and June 2014. In all, 12 (1.07\%) patients, 17 eyes were diagnosed with ocular syphilis. Briefly, 10 patients, 13 eyes had diagnosis of presumed latent ocular syphilis, and 2 patients, 4 eyes had diagnosis of presumed congenital late syphilis. Mean age at presentation was 43.75 years (range 8 and 67 years), and all of the patients were Caucasian. In all, 7 (58.3\%) were male and $5(41.7 \%)$ were female. Five $(41.6 \%)$ patients had bilateral involvement. The initial BCVA of the patients were between 20/400 and 20/20 (0-1.3 LogMAR) with a mean LogMAR visual acuity of 0.3 . None of the patients had elevated intraocular pressure (IOP). Demographics and clinical characteristics of the patients are summarized in Table 1 . One (5.8\%) eye had anterior scleritis (Figure 1A), one (5.8\%) eye had sclerokeratitis (Figure 2A), and five (20.9\%) eyes had non-granulomatous iridocyclitis that were resolved with frequent instillation of topical prednisolone acetate at the 10th day of PCN therapy (Figures 1B and 2B). Two (11.7) eyes had intermediate uveitis, 


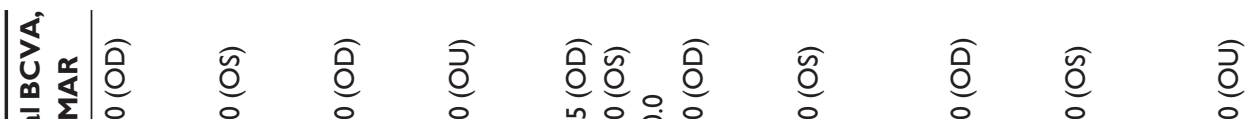

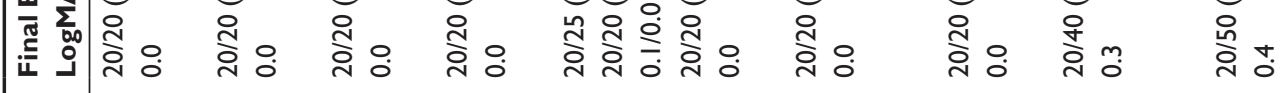

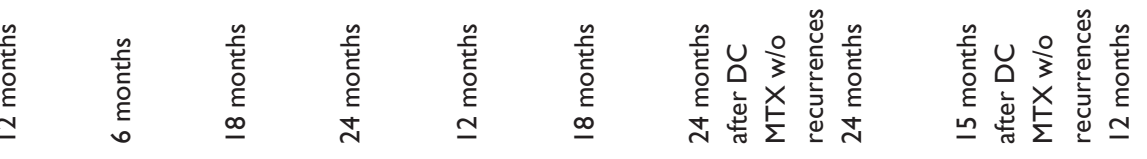

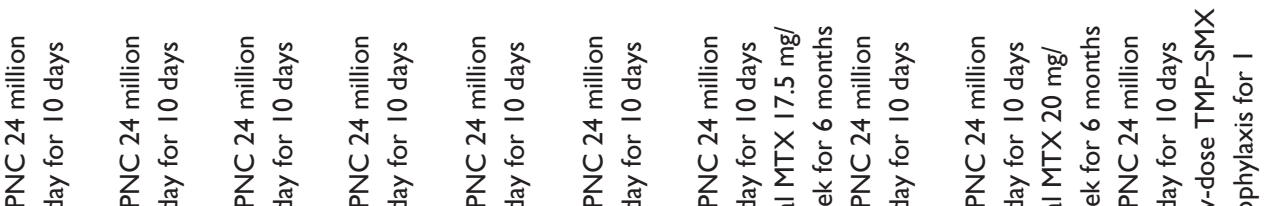

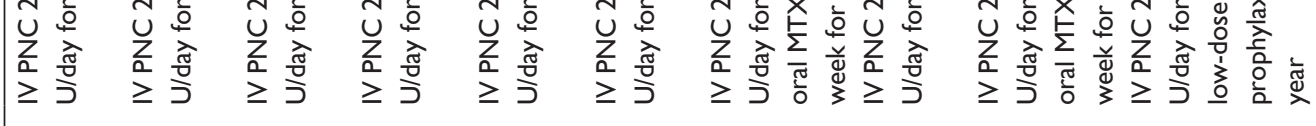

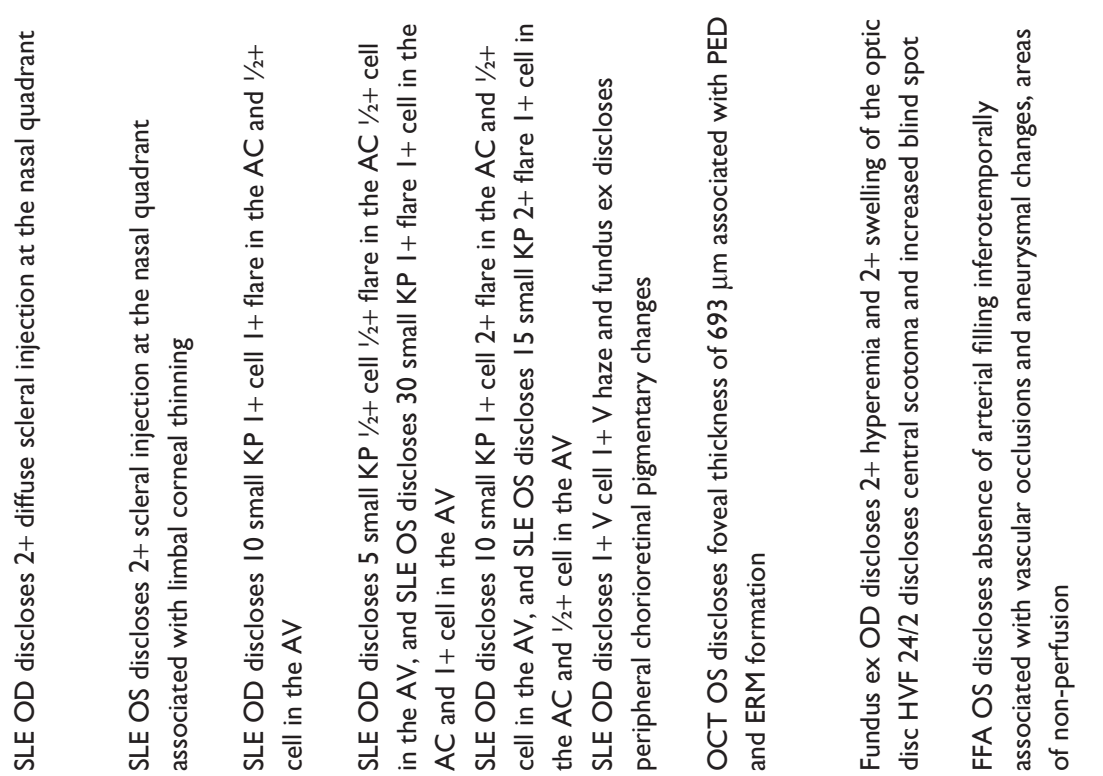

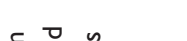

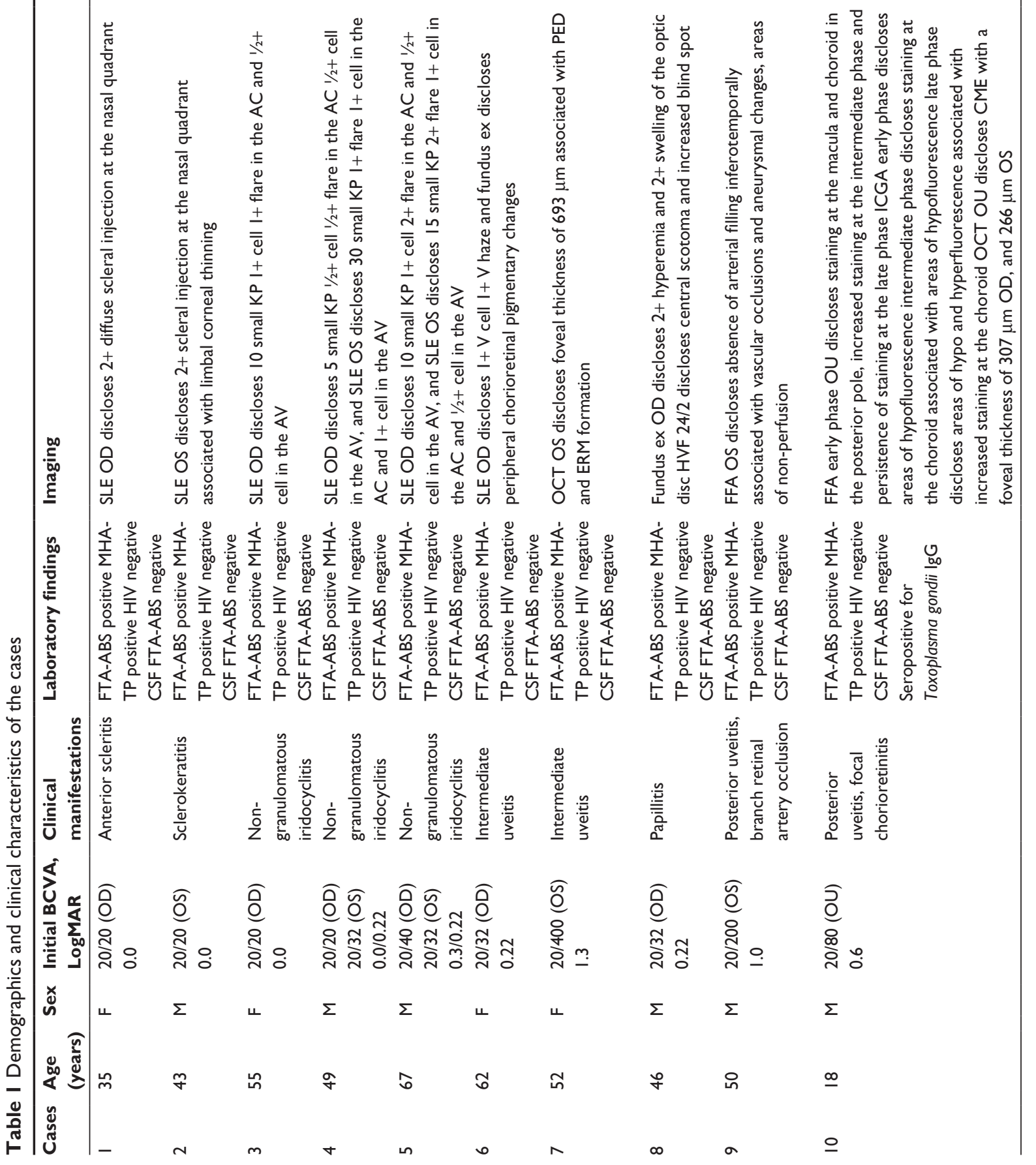



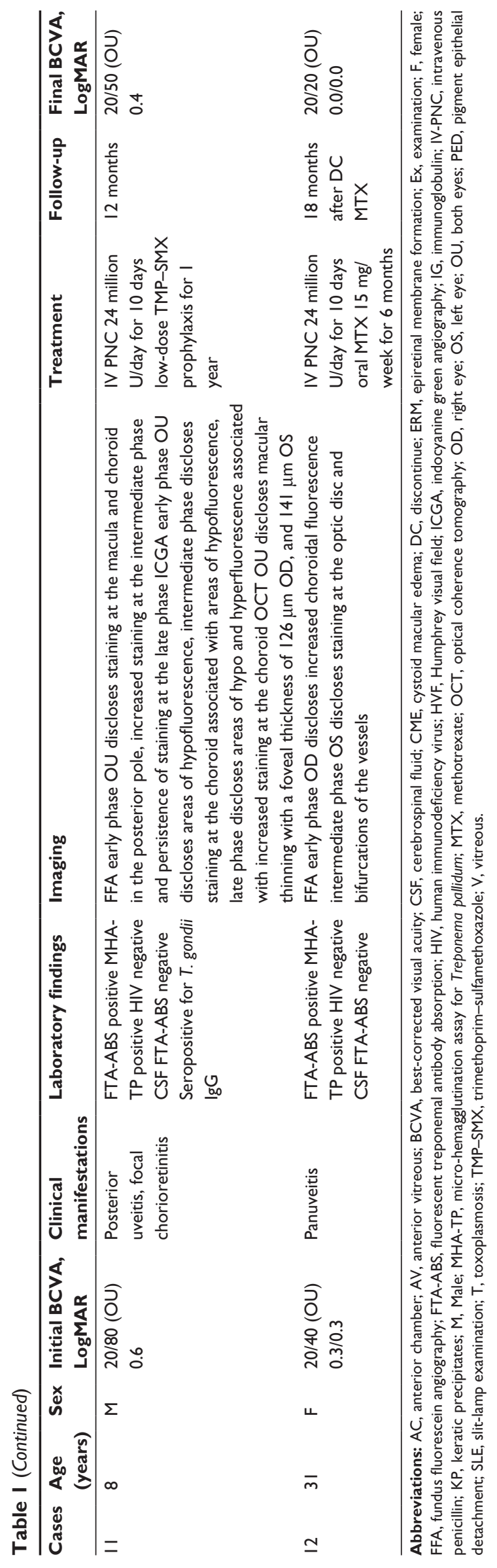

five (20.9\%) eyes had posterior uveitis, two (11.7\%) eyes had panuveitis, and one (5.8\%) eye had papillitis SD-OCT of one of the eyes with intermediate uveitis disclosed cystoid macular edema (CME) with a foveal thickness of $693 \mu \mathrm{m}$ associated with the retina pigment epithelial detachment (PED) and epiretinal membrane formation (Figure $3 \mathrm{~A}$ ) that showed regression of CME and PED with a foveal thickness of $362 \mu \mathrm{m}$ associated with persistence of epiretinal membrane at the $3 \mathrm{rd}$ month of the methotrexate (MTX) therapy (Figure 3B). The eyes with posterior uveitis had clinical manifestations of vitritis, branch retinal artery occlusion inferotemporally associated with vessel sheathing and intraretinal hemorrhages (Figure 4A), and focal chorioretinitis characterized by yellowish lesions with faded centers at the level of the pigment epithelium in the macula and paramacular region in both eyes of two patients (Figure 5A-D). Focal chorioretinitis was the most common posterior segment finding in our study (29.3\%). FFA late phase of the left eye with vitritis and branch retinal artery occlusion disclosed venous staining, leakage, and areas of non-perfusion (Figure 4B). FFA early phase of right and left eyes of the patient with focal chorioretinitis disclosed staining at the macula and choroid in the posterior pole, intermediate phase revealed increased staining, and late phase disclosed persistence of staining at the posterior pole (Figure 6Ai, Aii; Bi, Bii; and Ci, Cii). Indocyanine green angiography early phase of right and left eyes of the patient with focal chorioretinitis disclosed areas of hypofluorescence in the posterior pole, intermediate phase disclosed staining of choroid associated with areas of hypofluorescence, and late phase disclosed areas of hypo and hyperfluorescence associated with increased staining of choroid (Figure 7Ai, Aii; Bi, $\mathrm{Bii}$; and $\mathrm{Ci}, \mathrm{Cii}$ ). SD-OCT of right and left eyes of patient with focal chorioretinitis revealed CME with a right foveal thickness of $307 \mu \mathrm{m}$, and a left foveal thickness of $266 \mu \mathrm{m}$ (Figure 8A and B). SD-OCT of right and left eyes of the second patient with focal chorioretinitis disclosed right foveal thickness of 126 $\mu \mathrm{m}$, and left foveal thickness of $141 \mu \mathrm{m}$ (Figure $8 \mathrm{C}$ and D). The resolution of vitritis and intraretinal hemorrhages associated with persistence of arterial sheathing inferotemporally was noted for the patient with vitritis and branch retinal artery occlusion OS at the 3rd month of the MTX therapy (Figure 4C). FFA late venous phase disclosed decreased areas of non-perfusion, vascular leakage, and staining associated with the areas of capillary occlusions inferotemporally (Figure 4D). SD-OCT foveal thickness measurements of two patients with focal chorioretinitis in right and left eyes remained stable with treatment disclosing right foveal thickness of $131 \mu \mathrm{m}$, and left foveal thickness of $147 \mu \mathrm{m}$ for the first patient, and right foveal thickness of $368 \mu \mathrm{m}$, and left foveal thickness of $266 \mu \mathrm{m}$ at the 6th month of the follow-up exam (Figure 9A-D). The eyes 

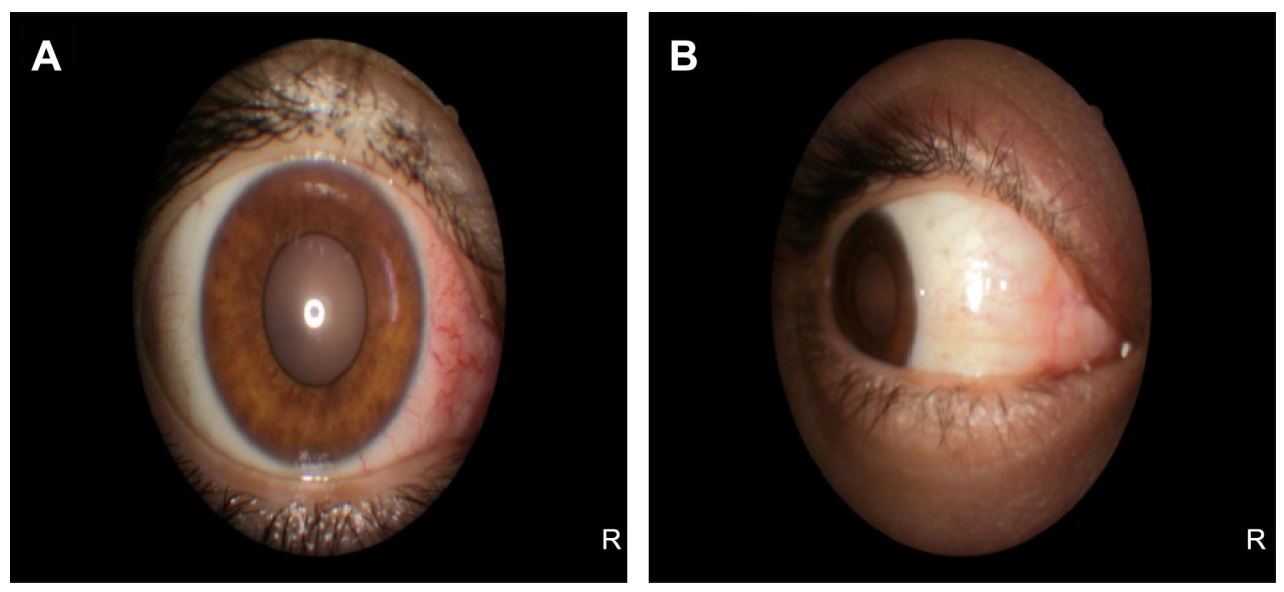

Figure I Represents the color photo of the right eye at pre-treatment and post-treatment phases.

Notes: (A) Color photo of right eye with anterior scleritis discloses 2+ diffuse sclera injection at the nasal quadrant. (B) Color photo of right eye with anterior scleritis discloses resolution of scleral injection with frequent instillation of topical prednisolone acetate at the 10th day of penicillin therapy.

with panuveitis disclosed creamy-yellow superficial retinal accumulations and optic disc congestion (Figure 10A and B). FFA early phase showed increased choroidal fluorescence OU (Figure 10C) and venous phase showed increased staining at the optic disc and bifurcation of the vessels OU (Figure 10D). The resolution of vitritis, the creamy-yellow superficial retinal accumulations and optic disc congestion were noted in right and left eyes of the patient with panuveitis at the 3rd month of the MTX therapy (Figure 10E and F). FFA arterial phase disclosed decreased choroidal fluorescence in right eye, and venous phase indicated the resolution of staining at the optic disc and bifurcations of the vessels in left eye (Figure 10G and $\mathrm{H})$. Fundus examination of the patient with right papillitis disclosed 2+ hyperemia and $2+$ swelling of the right optic disc (Figure 11A). Humphrey visual field analyzer 24-2 disclosed central scotoma and increased blind spot OD (Figure 11B). The resolution of optic disc congestion and edema OD with improvement of HVF 24-2 central scotoma in right eye at the 1st month of follow-up visit was noted for the patient with papillitis (Figure 11C and D). None of the patients were seropositive for HIV, and $2(16.6 \%)$ of the 12 patients were seropositive for $T$. gondii-specific IgG antibody. The CSF FTA-ABS analysis of all cases was negative. Elevated CSF protein was found in 2 cases who were seropositive for T. gondii-specific IgG antibody.

The patients who have received IV PNC only were followed-up 6 months to 2 years without recurrences. The patients who have received both IV PNC and oral MTX were followed-up 15-24 months period without recurrences. The final BCVA of the patients were between 20/50 and 20/20 (0.4-0.0 $\log$ MAR) with a mean LogMAR visual acuity of 0.06 . Focal chorioretinitis was found as the most common cause of visual impairment.

\section{Discussion}

Syphilis is a sexually transmitted infection (STI) with a steady increase in the number of infected cases in the USA since the middle of $1980 \mathrm{~s} .{ }^{14} \mathrm{~A}$ dramatic rise in incidence of primary

\section{A}

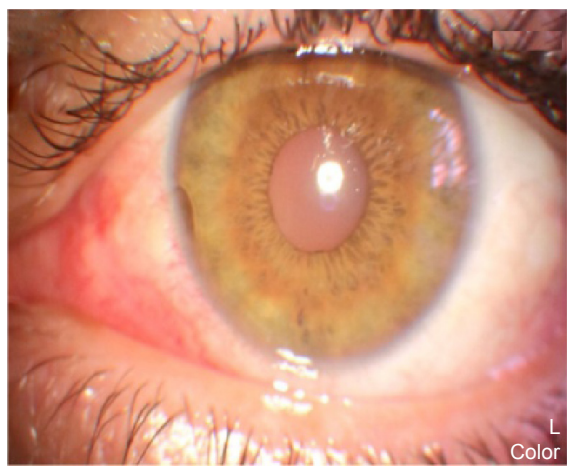

B

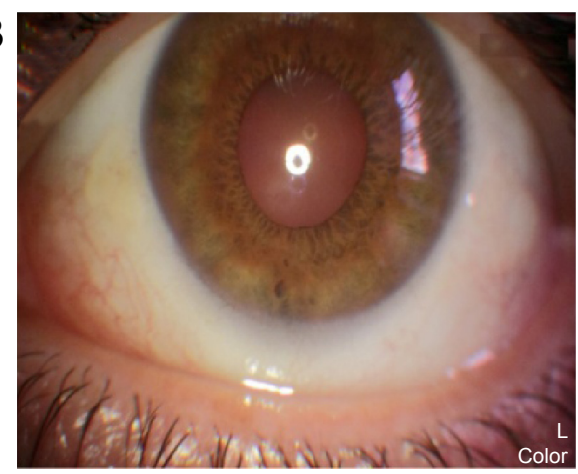

Figure 2 Represents the color photo of the left eye at pre-treatment and post-treatment phases.

Notes: (A) Color photo of left eye with sclerokeratitis discloses 2+ scleral injection at the nasal quadrant associated with limbal corneal thinning at 9 o'clock position.

(B) Color photo of left eye with sclerokeratitis discloses resolution of scleral injection and limbal corneal thinning with frequent instillation of topical prednisolone acetate at the I0th day of penicillin therapy. 

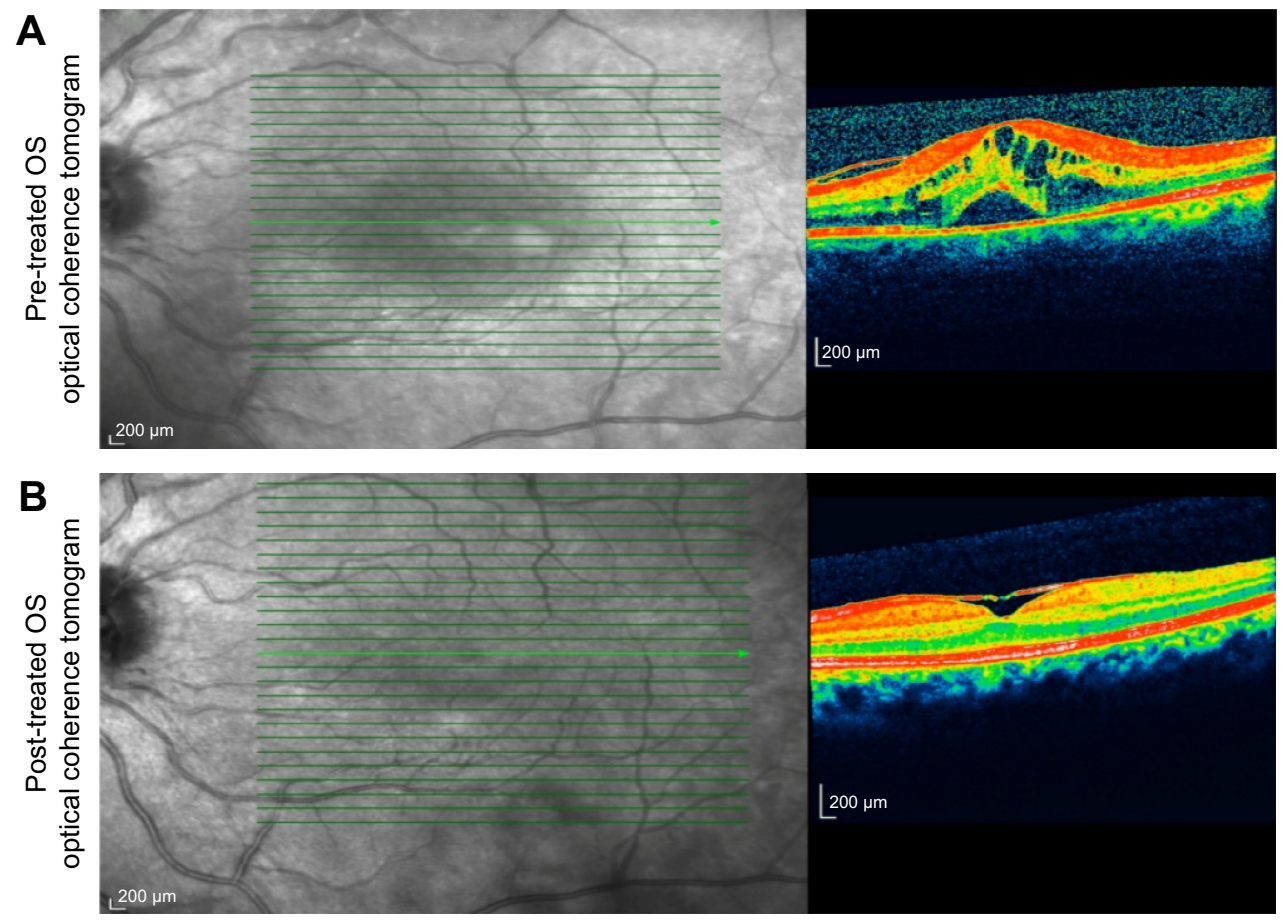

Figure 3 Represents the spectral domain optical coherence tomography of the left eye at pre-treatment and post-treatment phases.

Notes: (A) Spectral domain optical coherence tomography of the patient with intermediate uveitis disclosed left cystoid macular edema with a foveal thickness of $693 \mu \mathrm{m}$ associated with the retina pigment epithelial detachment and epiretinal membrane formation. (B) Spectral domain optical coherence tomography of the patient with intermediate uveitis disclosed regression of left cystoid macular edema and the retina pigment epithelial detachment with a foveal thickness of $362 \mu \mathrm{m}$ associated with persistence of epiretinal membrane formation at the 3rd month of the MTX therapy.

Abbreviations: MTX, methotrexate; OS, left eye.
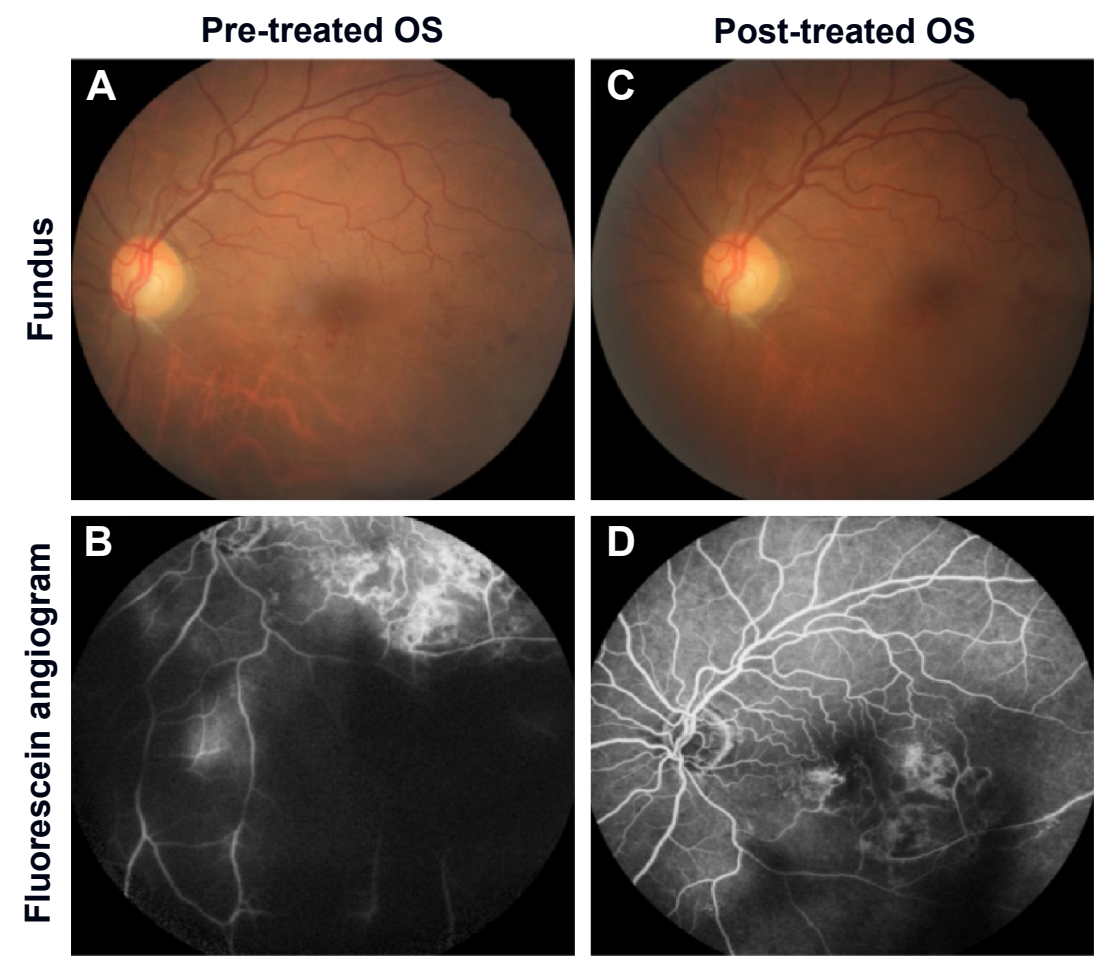

Figure 4 Represents the color fundus photo and fundus fluorescein angiography of the left eye at pre-treatment and post-treatment phases.

Notes: (A) Color fundus photo of left eye with posterior uveitis discloses vitritis and branch retinal artery occlusion inferotemporally associated with vessel sheathing and intraretinal hemorrhages. (B) Fundus fluorescein angiography late phase discloses venous staining, leakage, and areas of non-perfusion. (C) Color fundus photo discloses resolution of vitritis and intraretinal hemorrhages associated with persistence of arterial sheathing inferotemporally at the 3rd month of the MTX therapy. (D) Fundus fluorescein angiography late venous phase discloses decreased areas of non-perfusion, vascular leakage, and staining associated with the areas of capillary occlusions inferotemporally.

Abbreviations: MTX, methotrexate; OS, left eye. 

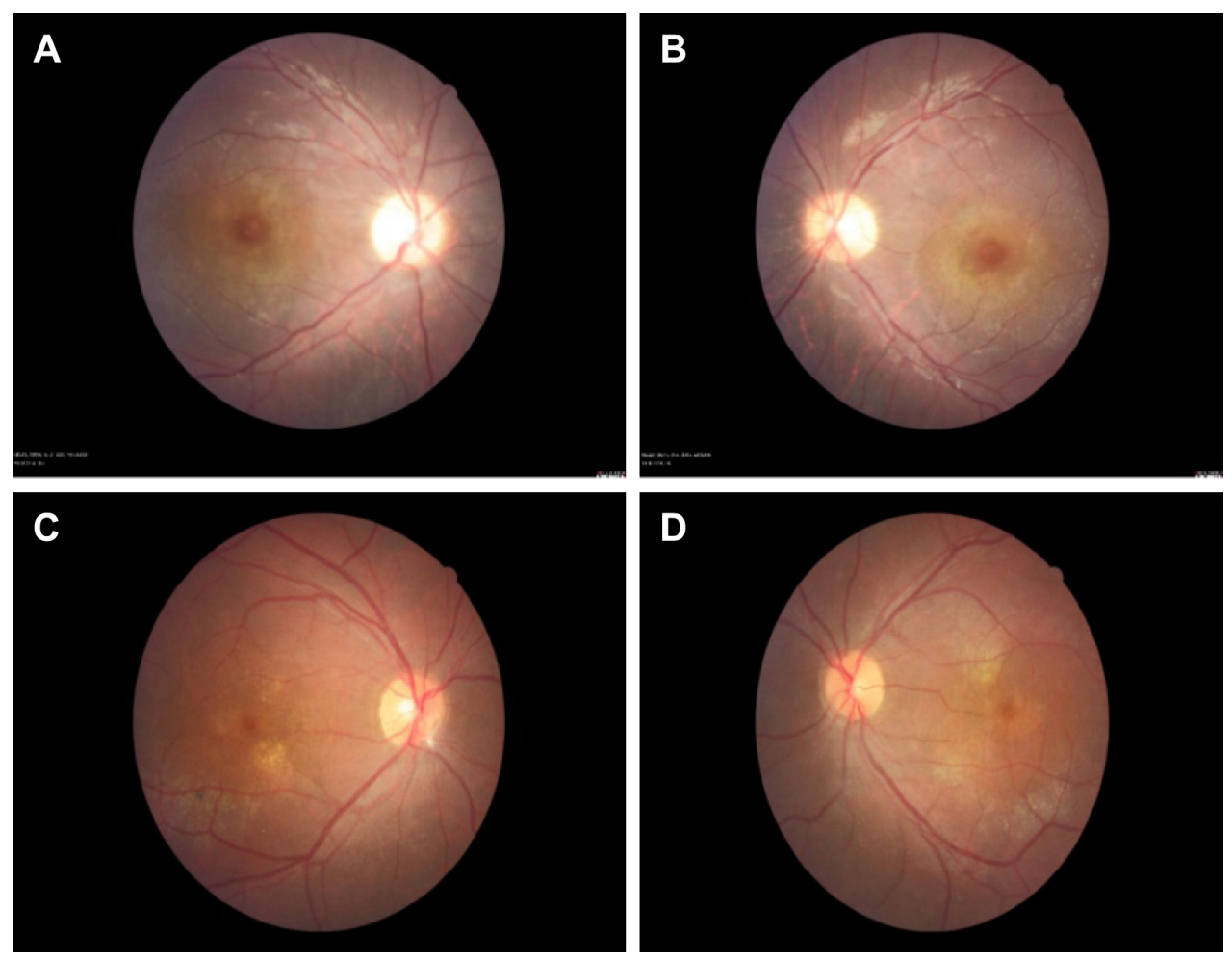

Figure $\mathbf{5}$ Represents the color fundus photos of the right and left eyes.

Notes: Color fundus photos of right eyes ( $\mathbf{A}$ and $\mathbf{C})$ and left eyes (B and $\mathbf{D})$ of two patients with focal chorioretinitis disclose yellowish lesions with faded centers at the level of the pigment epithelium in the macula and paramacular regions.

and secondary syphilis in the USA has been reported from 2.1 per 100,000 people in 2000 to 4.5 per 100,000 in $2011 .{ }^{15}$ The Centers for Disease Control and Prevention (CDC) has revealed that $72 \%$ of all primary and secondary syphilis cases occurred in men who have sex with men (MSM) in 2011 which has increased from $7 \%$ in $2000 .{ }^{16}$ In a study of MSM presented to sexually transmitted disease (STD) clinics, a higher proportion of primary and secondary syphilis has been noted in cases co-infected with HIV (10.1\%) than HIV-negative cases (2.6\%). ${ }^{17}$ Since 2001, threefold rise in incidence of syphilis and HIV infection in MSM have been reported in the age group of up to 25 years at the University Hospital of Dresen. ${ }^{18}$ The strong association between ocular syphilis co-infection with HIV has been considered to be related to genital ulcerative diseases that facilitate HIV infection. ${ }^{17}$ Our study disclosed the incidence of ocular syphilis among patients with ocular inflammation between January 2012 and June 2014 as $1.07 \%$. There was no comparable study related to the incidence of ocular syphilis in Turkey. However, RPR seropositivity among the blood donors at the central blood bank of Turkey has been reported to increase from $0.04 \%$ in 1987 to $0.2 \%$ in $2002 .{ }^{19}$ None of our cases were found seropositive for HIV. A low rate of HIV co-infection has also been reported in the first national seroprevalence survey in Saudi Arabia. ${ }^{20}$ This might be related to the sexual behaviors of individuals living in mostly Muslim populations. A steady increase, approximately 15 -fold in the incidence of ocular syphilis between 1999 and 2004, has also been reported in UK. ${ }^{21}$ The British Ocular Syphilis Study (BOSS) has revealed a total of 41 new cases (63 eyes) of intraocular syphilis between 2009 and 2011 with an annual incidence of 0.3 per million UK adult population. ${ }^{22}$ The mean age, sex distribution, and laterality of ocular involvement in BOSS were as 48.7 years, $90.2 \%$ male, and $56 \%$ bilateral involvement, respectively. ${ }^{22}$ Our study disclosed the mean age as 43.8 years, $58.3 \%$ male, and $41.6 \%$ bilateral involvement that were compatible with the BOSS study. Syphilis is considered to display diverse ophthalmologic manifestations. ${ }^{12,23}$ A case series study of ocular syphilis in 18 eyes of 12 patients in a Singaporean population between 2004 and 2009 disclosed that anterior uveitis and panuveitis were reported two most common findings. ${ }^{24}$ The other case series study including 22 patients with syphilitic uveitis followed at Singapore National Eye Center between 1995 and 2006 has revealed that non-granulomatous iridocyclitis was the most common finding $(62.1 \%)$ at presentation followed by panuveitis $(27.5 \%)$, posterior uveitis $(13.7 \%)$, and intermediate uveitis $(10.3 \%) .{ }^{25}$ This study also disclosed that vitritis $(65.4 \%)$ was the most common posterior segment finding. ${ }^{25}$ The most common posterior segment finding in our study was found as posterior 

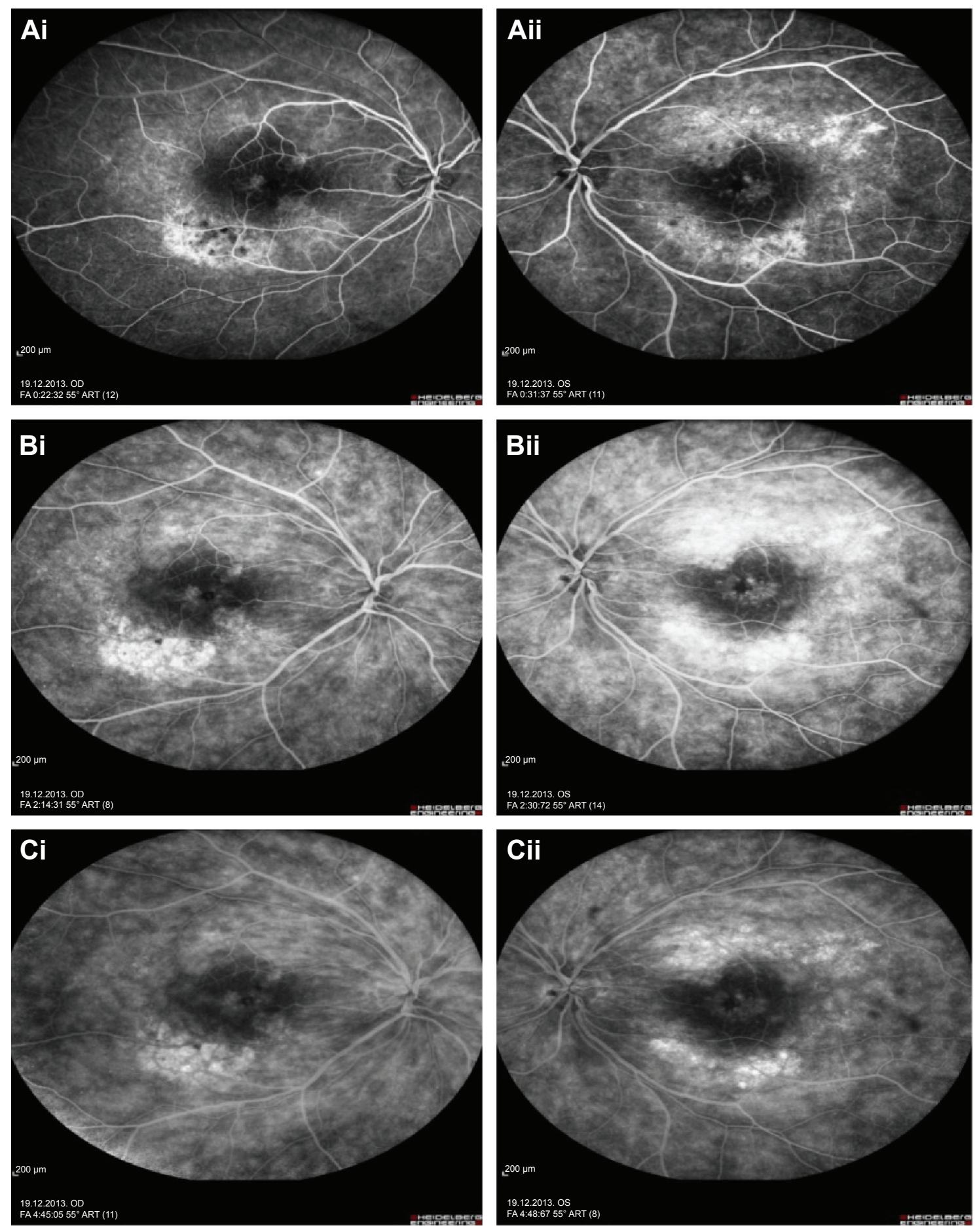

Figure 6 Represents the fundus fluorescein angiography of the right and left eye.

Notes: Fundus fluorescein angiography early phase of right and left eyes of the patient with focal chorioretinitis disclosed staining at the macula and choroid in the posterior pole (Ai and $\mathbf{A i i})$, intermediate phase revealed increased staining (Bi and $\mathbf{B i i})$, and late phase disclosed persistence of staining at the posterior pole ( $\mathbf{C i}$ and $\mathbf{C i i})$.

uveitis presenting as chorioretinitis rather than vitritis. In a study involving 35 eyes of 19 Chinese patients with syphilitic uveitis, posterior uveitis has been disclosed as the most common finding. ${ }^{26}$ In a recent study from the USA involving 61 eyes of 35 patients, independent of HIV status panuveitis was reported as the most common presentation in ocular syphilis. ${ }^{27}$ Our study disclosed that both non-granulomatous iridocyclitis (20.9\%) and posterior uveitis (20.9\%) were two most common presentations followed by panuveitis (11.7\%) and intermediate uveitis (11.7\%). Ocular syphilis was also 

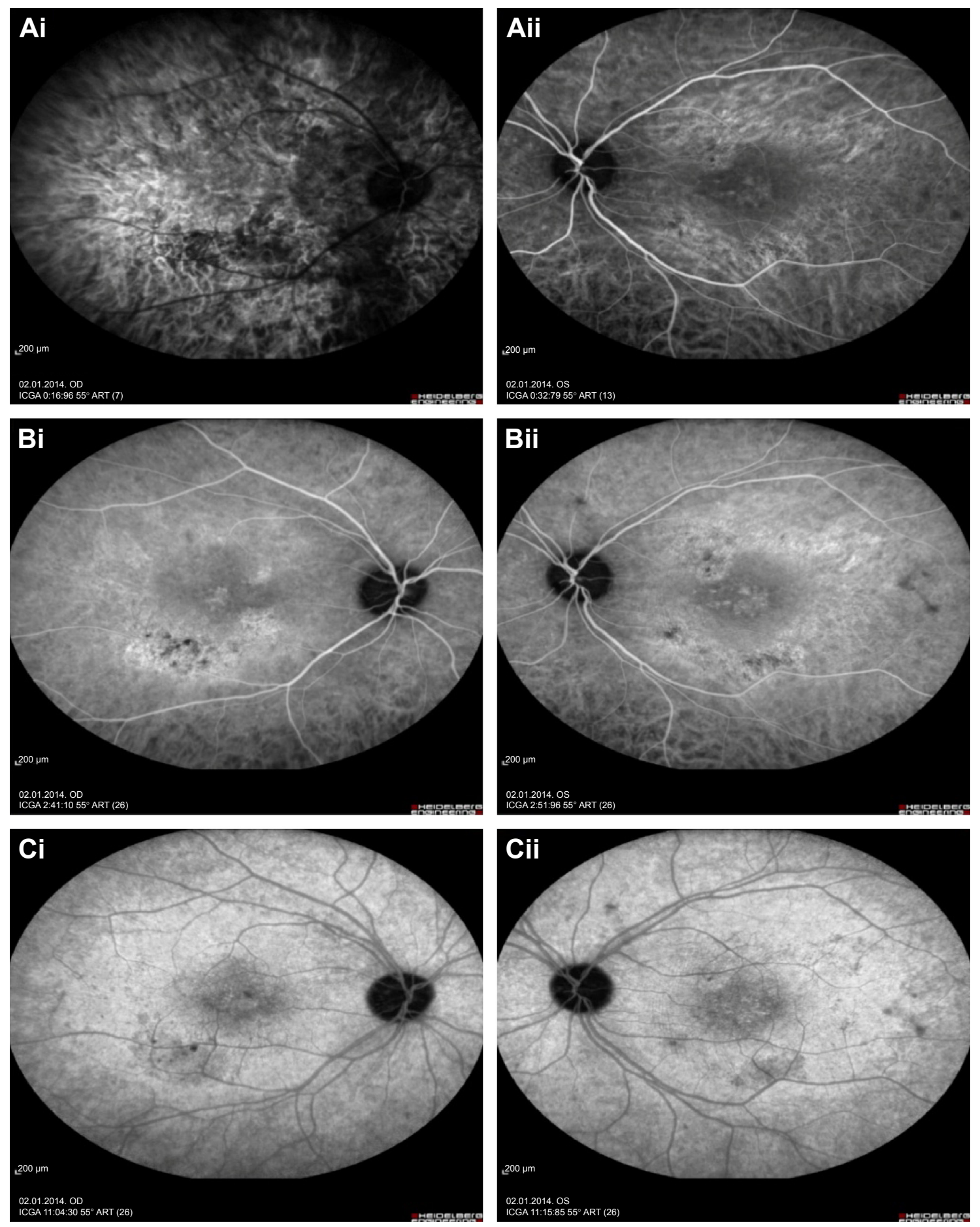

Figure 7 Represents the indocyanine green angiography of the right and left eye.

Notes: Indocyanine green angiography early phase of right and left eyes with focal chorioretinitis disclosed areas of hypofluorescence (Ai and $\mathbf{A i i})$, intermediate phase disclosed staining of choroid associated with areas of hypofluorescence (Bi and $\mathbf{B i i})$, and late phase disclosed areas of hypo and hyperfluorescence associated with increased staining of choroid in the posterior pole ( $\mathbf{C i}$ and $\mathbf{C i i})$.

reported to manifest as scleritis, episcleritis, or optic neuritis. ${ }^{28}$ Non-necrotizing anterior scleritis $(5.8 \%)$, non-necrotizing sclerokeratitis $(5.8 \%)$, and optic neuritis $(5.8 \%)$ were the least common findings in our study population. Since T. pallidum is a non-culturable bacteria, the diagnosis is considered to depend on mainly serological tests. ${ }^{29}$ Three syphilis testing algorithms - traditional algorithm, reverse algorithm, and the European Centre for Disease Prevention and Control (ECDC) algorithm have been reported among the serological diagnostic tests. ${ }^{29,30}$ The traditional algorithm 


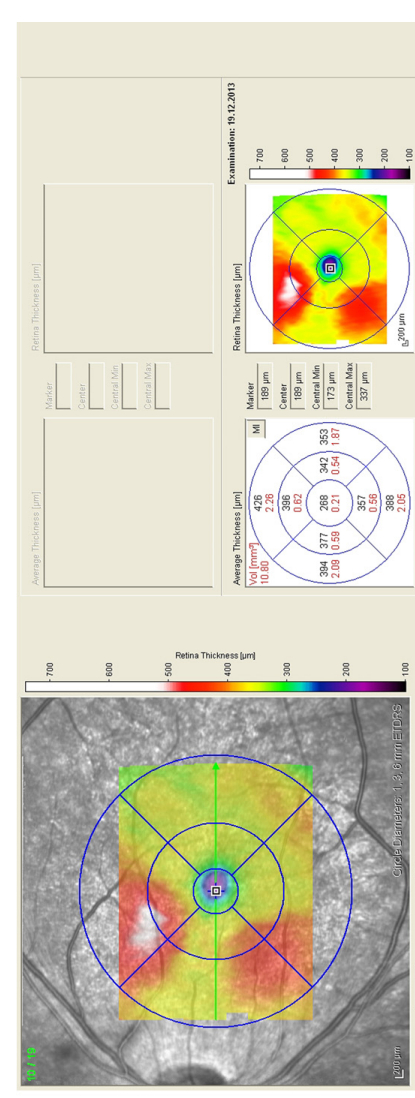

$m$

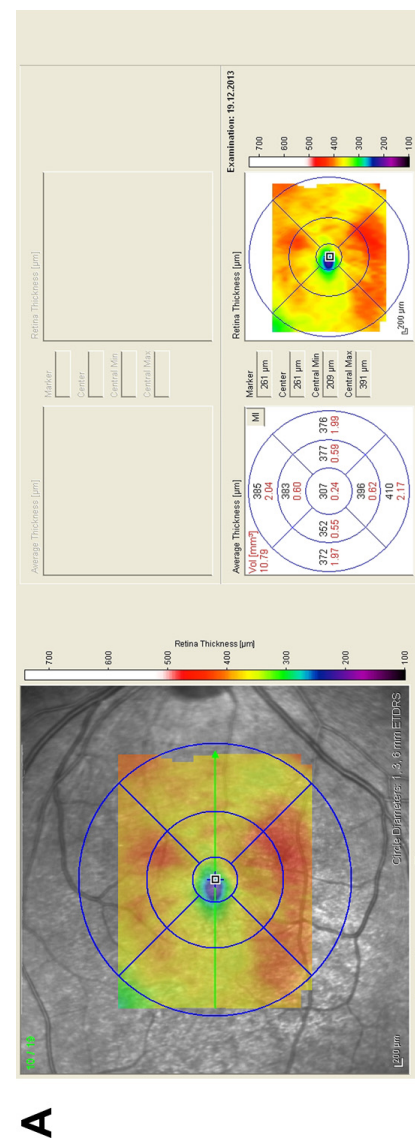

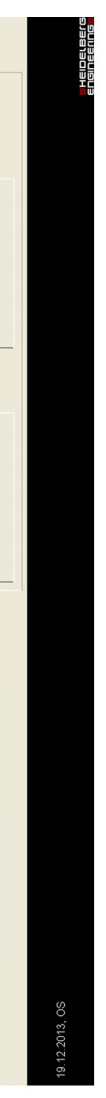

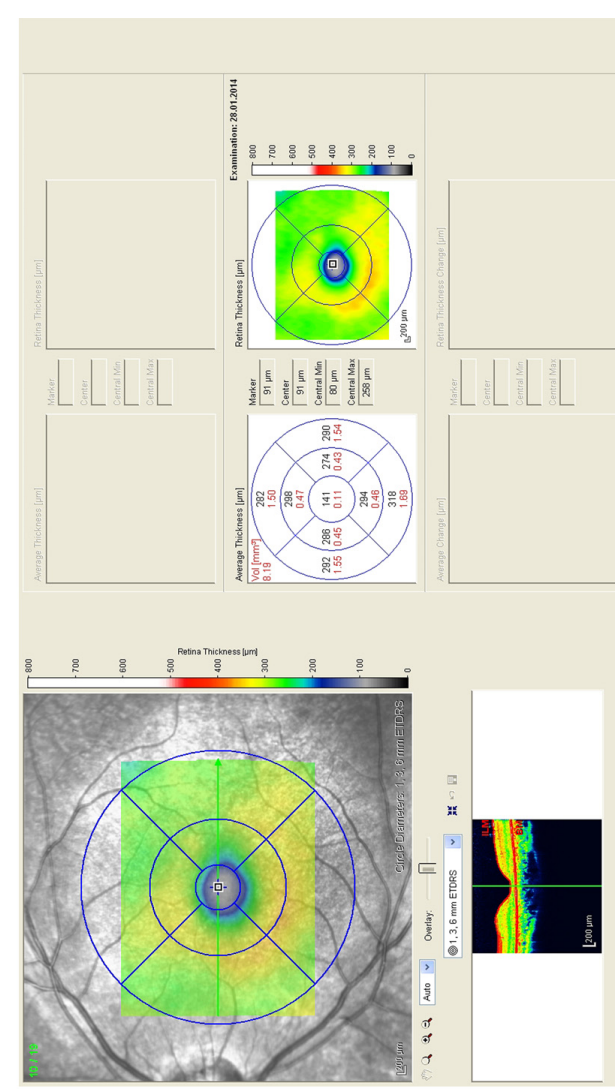

口
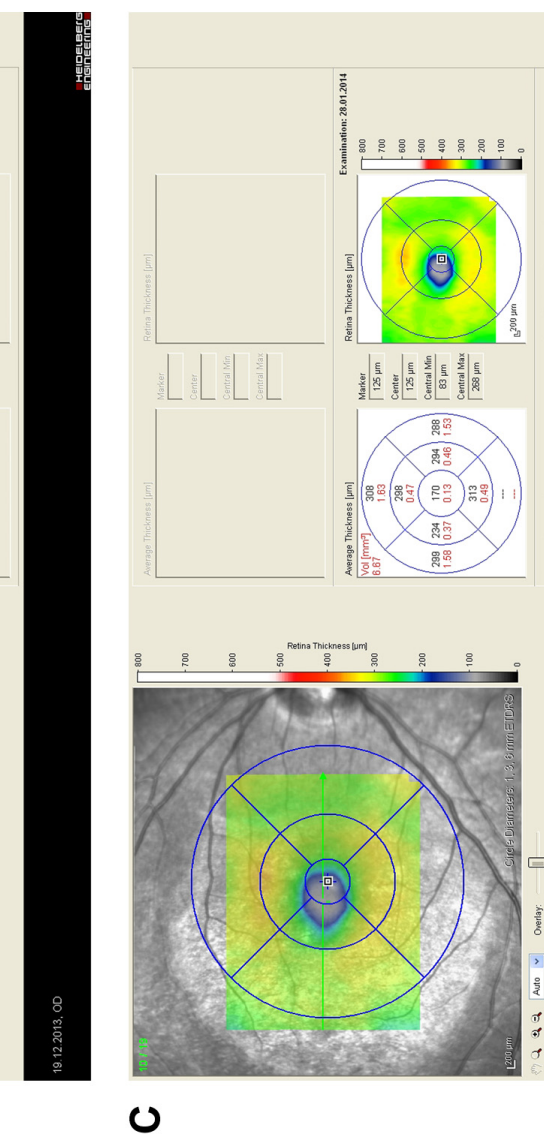

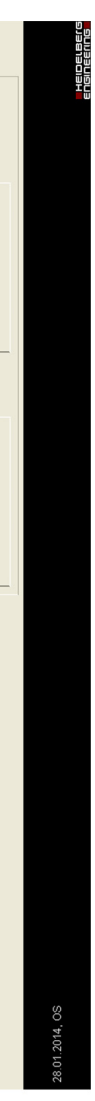

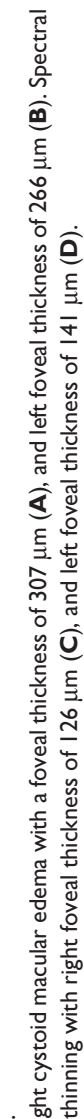

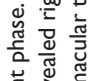

范

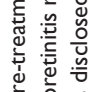

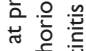

苍热

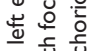

究

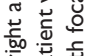

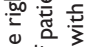

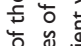

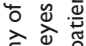

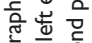

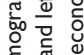

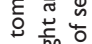

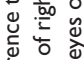

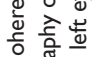

तु

言 施

동

흘

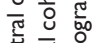

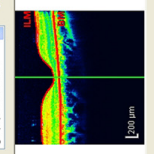

运 듬

告.

政

एक

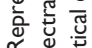

品 응

产造产 

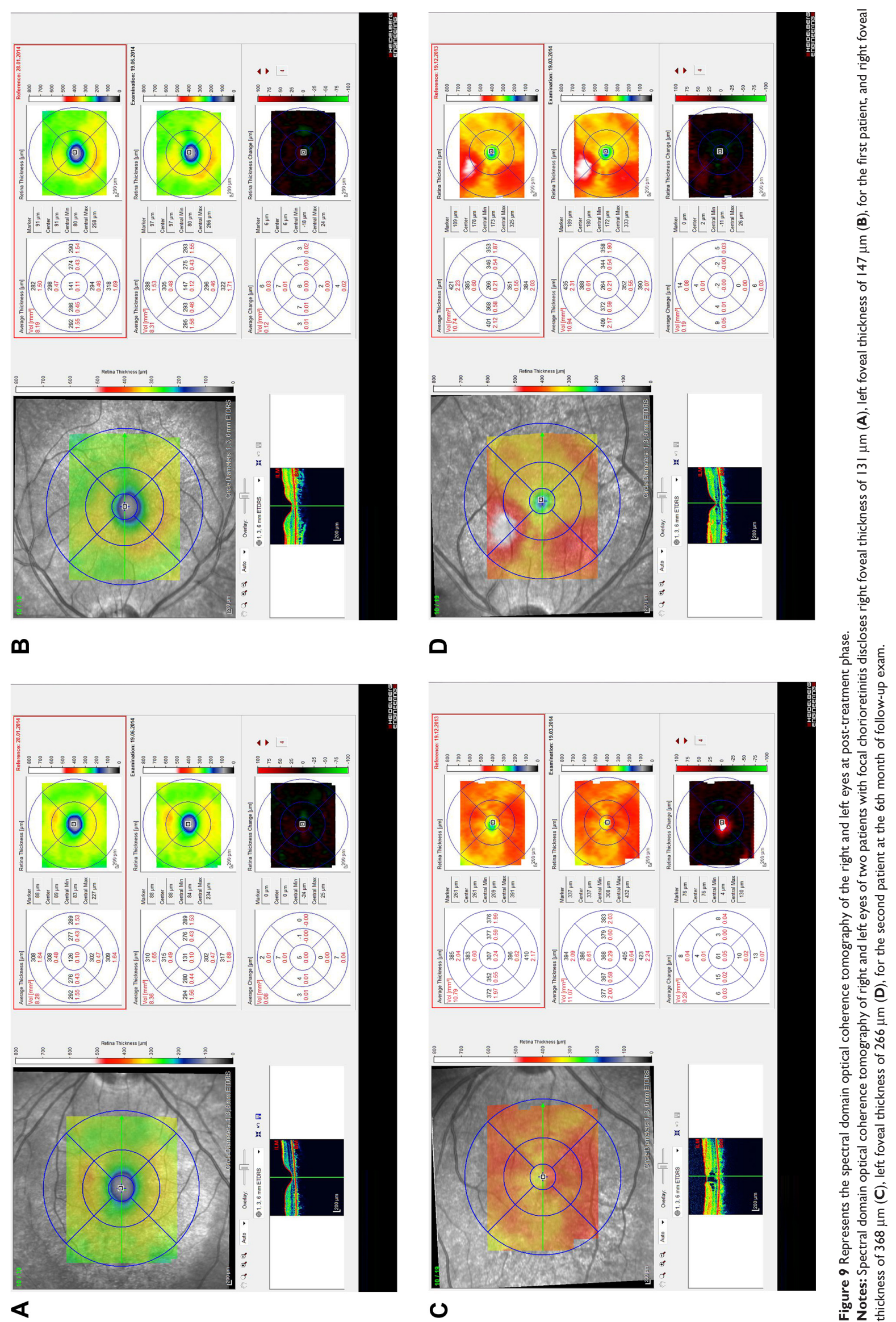


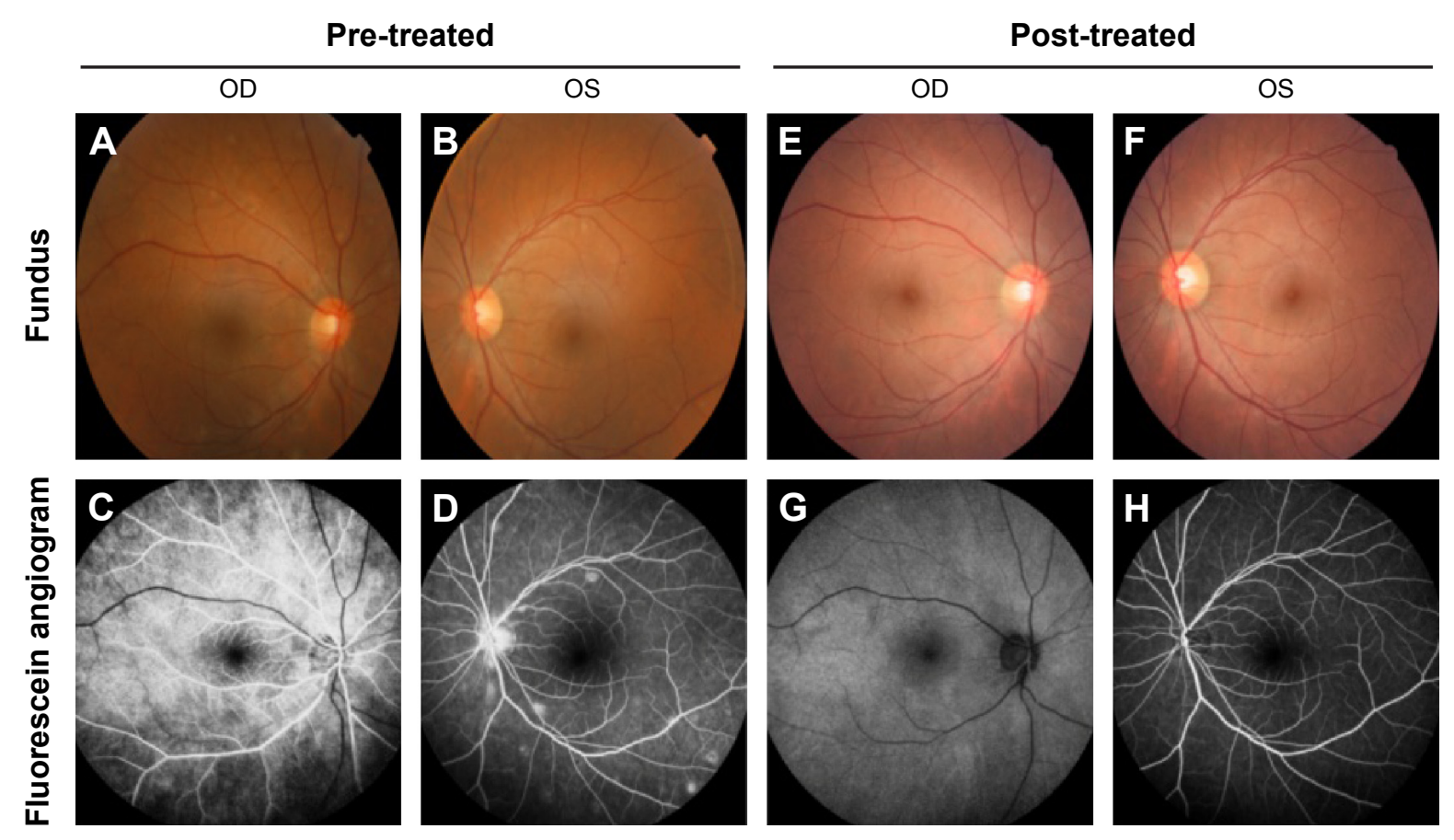

Figure 10 Represents the color fundus photo and fundus fluorescein angiography of the right and left eye at pre-treatment and post-treatment phases.

Notes: (A and B) Color fundus photo of right and left eyes with panuveitis disclosed creamy-yellow superficial retinal accumulations and optic disc congestion. (C) Fundus fluorescein angiography early phase showed increased choroidal fluorescence in the right eye, and (D) venous phase showed increased staining at the optic disc and bifurcation of the vessels in the left eye. (E, F) Color fundus photos of right and left eyes with panuveitis disclose resolution of vitritis, the creamy-yellow superficial retinal accumulations and optic disc congestion at the 3rd month of the MTX therapy. (G) Fundus fluorescein angiography arterial phase disclose decreased choroidal fluorescence in the right eye and $\mathbf{( H )}$ venous phase disclosed the resolution of staining at the optic disc and bifurcations of the vessels in the left eye.

Abbreviations: MTX, methotrexate; OS, left eye; OD, right eye.

uses a non-treponemal test, VDRL or RPR for screening, and screen-reactive samples are tested by a treponemal assay such as MHA-TP of FTA-ABS for confirmation. ${ }^{30}$ The reverse screening algorithm uses an automated, treponemal test such as enzyme immunoassay (EIA). ${ }^{30}$ Samples that are reactive by EIA are then tested by RPR to assess disease and treatment status. ${ }^{30}$ This technique allows clinical laboratories a rapid syphilis testing. ${ }^{30}$ However, the results of EIA screening and RPR are often reported discordant such as reactive by EIA and non-reactive by RPR. ${ }^{31}$ Centers for Disease Control and Prevention (CDC) recommends to perform MHA-TP to further analyze the discordant sera. ${ }^{31}$ A non-reactive MHA-TP result suggests that the results of EIA screening are falsely reactive, while a reactive MHA-TP result supports either a past, successfully treated syphilis or late/latent syphilis. ${ }^{32}$ The European Centre for Disease Prevention and Control algorithm uses a treponemal immunoassay that is followed by a second, different treponemal assay as a confirmatory test in high-prevalence populations. ${ }^{32} \mathrm{We}$ used the traditional algorithm for the serological diagnosis of syphilis in our study.

T. pallidum disseminates to the central nervous system within days after exposure. ${ }^{33}$ Neurological involvement is reported to occur during any stage of the infection, and it is manifested as asymptomatic neurosyphilis, acute meningeal syphilis, meningovascular syphilis, paretic neurosyphilis, and tabetic neurosyphilis. ${ }^{33,34}$ Syphilis-specific CSF diagnostic tests including CSF VDRL, FTA-ABS, or PCR for T. pallidum DNA are recommended whenever any additional signs of neurosyphilis such as headache, hypoacusis, tinnitus, cranial nerve abnormalities, and motor and sensory symptoms occur. ${ }^{35}$ The majority of cases of neurosyphilis are reported in HIV-infected patients. ${ }^{36,37}$ This is considered to be associated impaired control of syphilis infection due to compromised host immune activity as a result of HIV co-infection. ${ }^{36}$ Especially, HIV-patients with a CD 4 count of $<350$ cells $/ \mu \mathrm{L}$ seem to be under a higher risk of developing CSF and neurological abnormalities most likely meningitis. ${ }^{37}$

Co-infections with other causes of STI such as Neisseria gonorrhea, Herpes simplex virus 2, Chlamydia trachomatis, Hepatitis $\mathrm{B}$ and Hepatitis $\mathrm{C}$ virus and Trichomonas vaginalis are reported to be prevalent in developing countries. ${ }^{38-41}$ The incidence of syphilis between 1990 and 1996 in Slovak Republic has been reported to increase nearly five times, and the patients have been most commonly co-infected with Neisseria gonorrhea.$^{38}$ Increased number of cases of 


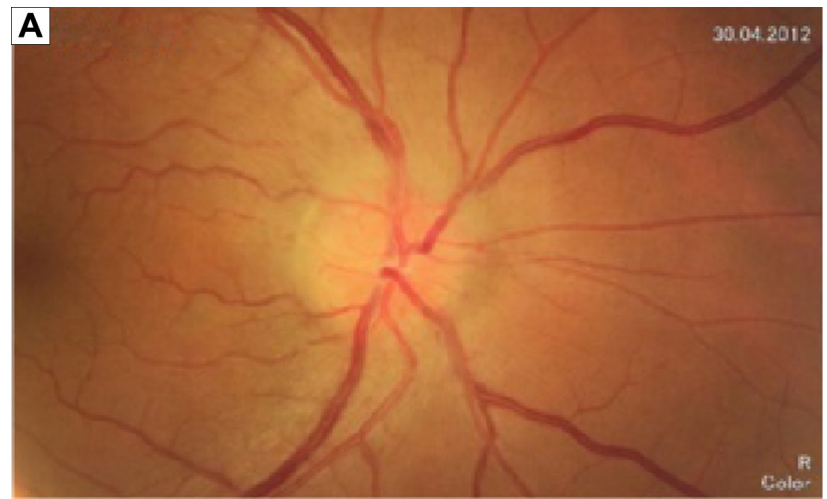

B SINGLE FIELD ANALYSIS

EYE: RIGHT

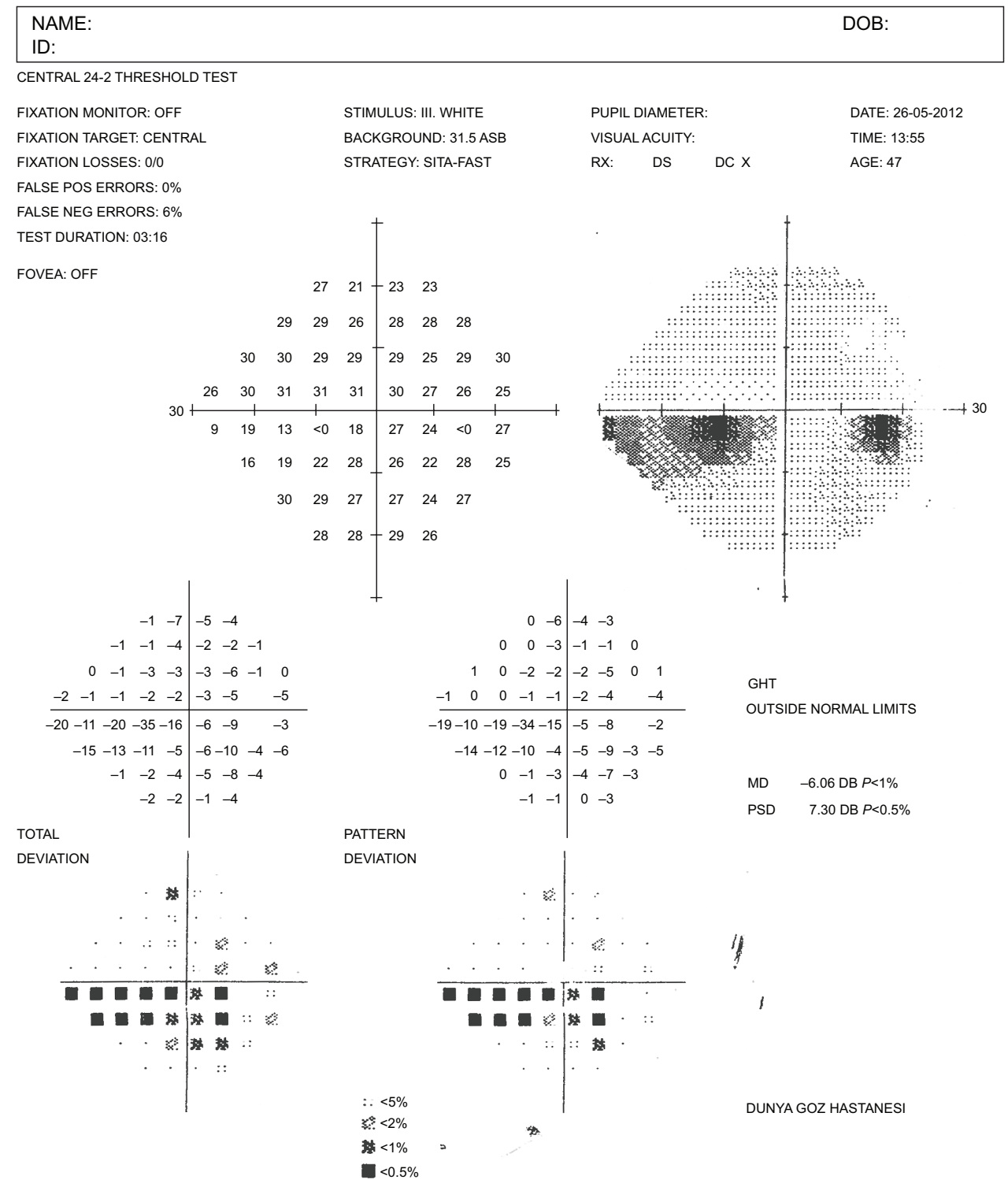

2005 CARL ZEISS MEDITEC

HFA II 750-9335-4.1/4.1

Figure II (Continued) 


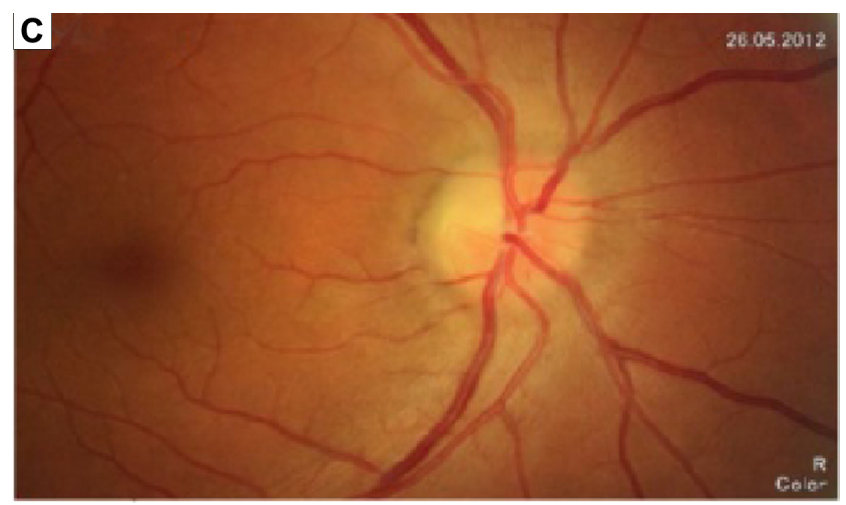

D

SINGLE FIELD ANALYSIS

EYE: RIGHT

NAME:

ID:

DOB:

CENTRAL 24-2 THRESHOLD TEST

FIXATION MONITOR: OFF

FIXATION TARGET: CENTRAL

FIXATION LOSSES: $0 / 0$

STIMULUS: III. WHITE

BACKGROUND: 31.5 ASB

PUPIL DIAMETER:

VISUAL ACUITY:

RX: DS DC $X$

DATE: $26-05-2012$

FALSE POS ERRORS: $2 \%$

FALSE NEG ERRORS: $6 \%$

TEST DURATION: 03:08

FOVEA: OFF
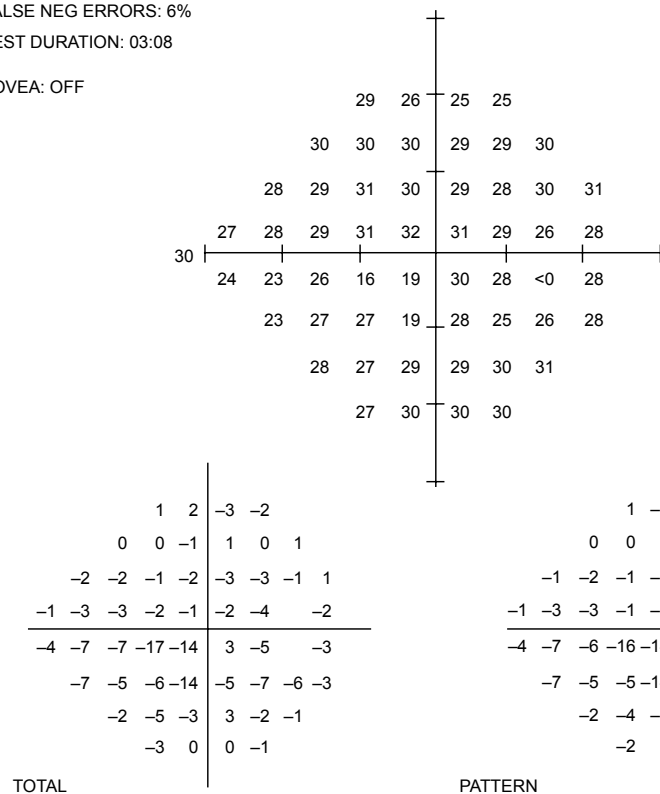

$+$

DEVIATION

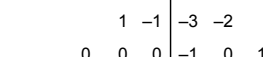

\begin{tabular}{ccc|ccc}
0 & 0 & 0 & -1 & 0 & 1
\end{tabular}

\begin{tabular}{llll|llll}
-1 & -2 & -1 & -2 & -3 & -3 & 0 & 1
\end{tabular}

\begin{tabular}{ccccc|ccc}
-1 & -3 & -3 & -1 & -1 & -1 & -3 & -2 \\
\hline-4 & -7 & -6 & -16 & -14 & -3 & -5 & -3
\end{tabular}

GHT

OUTSIDE NORMAL LIMITS

$\begin{array}{llllllll}-7 & -5 & -5 & -14 & -5 & -7 & -5 & -2\end{array}$

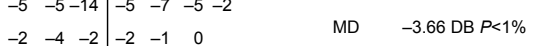

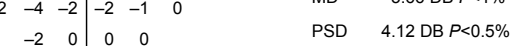

PATTERN

DEVIATION

1

$\begin{array}{ll}0 & 0\end{array}$

TIME: 13:25

AGE: 47

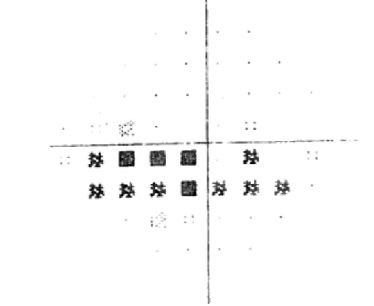

$$
\begin{aligned}
& :<<\% \\
& z<2 \% \\
& z<1 \% \\
& z<0.5 \%
\end{aligned}
$$

DUNYA GOZ HASTANESI

פ2005 CARL ZEISS MEDITEC

HFA II 750-9335-4.1/4.1

Figure II Represents the color fundus photo and Humphrey visual field 24-2 of the right eye at pre-treatment and post-treatment phases.

Notes: (A) Color fundus photo of the patient with right papillitis discloses $2+$ hyperemia and $2+$ swelling of the optic disc. (B) Humphrey visual field $24-2$ discloses right central scotoma and increased blind spot. (C) Color fundus photo of the right eye discloses resolution of optic disc congestion and edema at the I st month of follow-up visit. (D) Humphrey visual field 24-2 discloses improvement of central scotoma at the Ist month of follow-up visit. 
syphilis in the Black Sea region of Turkey has been reported between the years 1992 and 1994 related to unprotected sex, promiscuity, and prostitution. ${ }^{39}$ The incidence of syphilis in pregnant women has also noted to increase in Slovak Republic between 1990 and 1996 with the stable number of cases with CS. ${ }^{38}$ TORCHES (toxoplasmosis, rubella, cytomegalic inclusion disease, herpes virus including EpsteinBarr, syphilis) was defined as congenital co-infection with more than one pathogens, and it was considered as an infectious etiology of congenital cataract. ${ }^{41-45} \mathrm{CS}$ and congenital toxoplasmosis are more frequent infectious causes of congenital blindness or visual impairment. ${ }^{42,43}$ Rare cases of CS co-infected with congenital rubella and congenital toxoplasmosis co-infected with congenital rubella have been described. ${ }^{44}$ However, co-infected with $T$. gondii in congenital ocular syphilis has been scarcely described in the literature. ${ }^{45}$ Our study disclosed that two of the cases who were siblings with congenital late syphilis were seropositive for $T$. gondii-specific IgG antibody. The cause of their visual impairments was related to posterior uveitis presented as central retinochoroiditis.

Chorioretinitis in the macula and delay in diagnosis were related to visual loss in patients with ocular syphilis. ${ }^{27}$ The BCVAs of our patients with CS showed slight improvement from 20/80 to 20/50 with IV PCN and low-dose TMP-SMX which was considered as prophylaxis related to the presence of risk factor that was seropositivity for syphilis.

MTX has been considered to have an adjunctive role to suppress intraocular inflammation, reduce uveitic macular edema, and prevent the recurrences of the disease. ${ }^{46}$ Cases 1-3 received adjunctive therapy with MTX after specific therapy with IV PCN to resolve the residual intraocular inflammation and CME.

\section{Conclusion}

Ocular syphilis is uncommon cause of ocular inflammation in HIV-negative patients. Central retinochoroiditis is the most common ocular manifestation, and it is the most common cause of visual impairment. Ocular syphilis might present associated with co-infections such as $T$. gondii in developing countries. Oral MTX might be beneficial as an adjunctive therapy for ocular syphilis in resolving the residual intraocular inflammation and $\mathrm{CME}$ after specific therapy with IV PCN.

\section{Disclosure}

The authors report no conflicts of interest in this work.

\section{References}

1. Hook EW, Marra CM. Acquired syphilis in adults. $N$ Engl J Med. 1992;326(16):1060-1069.

2. Phiske MM. Current trends in congenital syphilis. Indian J Sex Transm Dis. 2014;35(1):12-20.

3. Mindel A, Tovey SJ, Timmins DJ, Williams P. Primary and secondary syphilis, 20 years' experience. 2. Clinical features. Genitourin Med. 1989;65(1):1-3.

4. Chapel TA. The signs and symptoms of secondary syphilis. Sex Transm Dis. 1980;7(4):161-164.

5. Cohen SE, Klausner JD, Engelman J, Philip S. Syphilis in modern era: an update for physicians. Infect Dis Clin North Am. 2013;27(4): 705-722.

6. Handsfield HH, Lukehart SA, Sell S, Norris SJ, Holmes KK. Demonstration of Treponema pallidum in a cutaneous gumma by indirect immunofluorescence. Arch Dermatol. 1983;119(8):677-680.

7. Jantzen SU, Ferrea S, Langebner T, et al. Late-stage neurosyphilis presenting with severe neuropsychiatric deficits: diagnosis, therapy, and course of three patients. J Neurol. 2012;259(4):720-728.

8. Kampmeier RH. Neurosyphilis. Am Pract Dig Treat. 1948;2(8): 523-525.

9. Aldave AJ, King JA, Cunningham ET Jr. Ocular syphilis. Curr Opin Ophthalmol. 2001;12(6):433-441.

10. De Santis M, De Luca C, Mappa I, et al. Syphilis infection during pregnancy: fetal risks and clinical management. Infect Dis Obstet Gynecol. 2012;2012:430585.

11. Shaparenko MV, Anton'ev AA, Milich MV. The clinical and serological characteristics of early congenital syphilis today. Vestn Dermatol Venerol. 1990;(7):16-20.

12. Margo CE, Hamed LM. Ocular syphilis. Surv Ophthalmol. 1992;37(3): 203-220.

13. Morshed MG. Current trend on syphilis diagnosis: issues and challenges. Adv Exp Med Biol. 2014;808:51-64.

14. Kent ME, Romanelli F. Reexamining syphilis: an update on epidemiology, clinical manifestations, and management. Ann Pharmacother. 2008;42(2):226-236.

15. Mattei PL, Beachkofsky TM, Gilson RT, Wisco OJ. Syphilis: a reemerging infection. Am Fam Physician. 2012;86(5):433-440.

16. Centers for Disease Control and Prevention (CDC). Primary and secondary syphilis - United States, 2003-2004. MMWR Morb Mortal Wkly Rep. 2006;55(10):269-273.

17. Bernstein KT, Stephens SC, Strona FV, Kohn RP, Philip SS. Epidemiologic characteristics of ongoing syphilis epidemic among men who have sex with men, San Francisco. Sex Transm Dis. 2013;40(1):11-17.

18. Spornraft-Ragaller P, Schmitt J, Stephan V, Boashie U, Beissert S. Characteristics and coinfection with syphilis in newly HIV-infected patients at the University Hospital Dresden 1987-2012. J Dtsch Dermatol Ges. 2014;12(8):707-716.

19. Kocak N, Hepgul S, Ozbayburtlu S, et al. Trends in major transfusiontransmissible infections among blood donors over 17 years in Istanbul, Turkey. J Int Med Res. 2004;32(6):671-675.

20. Memish ZA, Almasri M, Chentoufi AA, et al. Seroprevalence of Herpes Simplex Virus Type 1 and Type 2 and coinfection with HIV and syphilis: the first national seroprevalence survey in Saudi Arabia. Sex Transm Dis. 2015;42(9):526-532.

21. Dorris JP, Saha K, Jones NP, Sukthankar A. Ocular syphilis: the new epidemic. Eye. 2006;20(6):703-705.

22. Mathew RG, Goh BT, Westcott MC. British Ocular Syphilis Study (BOSS): 2-year national surveillance study of intraocular inflammation secondary to ocular syphilis. Invest Ophthalmol Vis Sci. 2014;55(8): 5394-5400.

23. Hughes EH, Guzowski M, Simunovic MP, Hunyor AP, McCluskey P. Syphilitic retinitis and uveitis in HIV-positive adults. Clin Exp Ophthalmol. 2010;38(9):851-856.

24. Yap SC, Tan YL, Chio MT, Teoh SC. Syphilitic uveitis in a Singaporean population. Ocul Immunol Inflamm. 2014;22(1):9-14. 
25. Anshu A, Chenq CL, Chee SP. Syphilitic uveitis: an Asian perspective. Br J Ophthalmol. 2008;92(5):594-597.

26. Yang P, Zhang N, Li F, Chen Y, Kijlstra A. Ocular manifestations of syphilitic uveitis in Chinese patients. Retina. 2012;32(9):1906-1914.

27. Moradi A, Salek S, Daniel E, et al. Clinical features and incidence rates of ocular complications in patients with ocular syphilis. Am J Ophthalmol. 2015;159(2):334-343.

28. Puech C, Gennai S, Pavese P, et al. Ocular manifestations of syphilis: Recent cases over a 2.5-year period. Graefes Arch Clin Exp Ophthalmol. 2010;248(11):1623-1629.

29. Morshed MG. Current trend on syphilis diagnosis: issues and challenges. Adv Exp Med Biol. 2014;808:51-64.

30. Tong ML, Lin LR, Liu LL, et al. Analysis of 3 algorithms for syphilis serodiagnosis and implications for clinical management. Clin Infect Dis. 2014;58(8):1116-1124.

31. Binnicker MJ, Jespersen DJ, Rollins LO. Direct comparison of the traditional and reverse screening algorithms in a population with a low prevalence of syphilis. J Clin Microbiol. 2012;50(1):148-150.

32. Sena AC, White BL, Sparling PF. Novel Treponema pallidum serologic tests: a paradigm shift in syphilis screening for the 21 st century. Clin Infect Dis. 2010;51(6):700-770.

33. Simon R. The great pox. Clin Infect Dis. 2004;38(7):1007-1008.

34. Ghanem KG. Neurosyphilis: a historical perspective and review. CNS Neurosci Ther. 2010;16(5):157-168.

35. Timmermans M, Carr J. Neurosyphilis in the modern era. $J$ Neurol Neurosurg Psychiatry. 2004;75(12):1727-1730.

36. Chan DJ. Syphilis and HIV co-infection: when is lumbar puncture indicated? Curr HIV Res. 2005;3(1):95-98.

37. Lynn WA, Lightman S. Syphilis and HIV: a dangerous combination. Lancet Infect Dis. 2004;4(7):456-466.
38. Hegyi V, Danilla T, Hegyi E. Actual trends of the incidence of syphilis and gonorrhea in the Slovak Republic in the year 1990-1996. Sex Transm Inf. 1998;74(5):376.

39. Apaydın R, Bilen N, Gül U, Bahadır S. Increased number of cases of syphilis in Trabzon, a trade city in the Black Sea region of Turkey. Sex Transm Inf. 1998;74(5):377.

40. Makasa M, Buve A, Sandoy IF. Etiologic pattern of genital ulcers in Lusaka, Zambia: has chancroid been eliminated? Sex Transm Dis. 2012; 39(10):787-791.

41. Tiruneh M. Seroprevalence of multiple sexually transmitted infections among antenatal clinic attendees in Gonar Health Center, northwest Ethiopia. Ethiop Med J. 2008;46(4):359-366.

42. Mahalakshmi B, Therese KL, Devipriya U, Pushpalatha V, Margarita S, Madhavan HN. Infectious etiology of congenital cataract based on TORCHES screening in a tertiary eye hospital in Chennai, Tamil Nadu, India. Indian J Med Res. 2010;131:559-564.

43. Thapliyal N, Shukla PK, Kumar B, Upadhyay S, Jain G. TORCH infection in women with bad obsteric history - a pilot study in Kumaon region. Indian J Pathol Microbiol. 2005;48(4):551-553.

44. Souza Rda S, Araújo BF, et al. Prevalence of toxoplasmosis, HIV, syphilis and rubella in a population of puerperal women using Whatman 903 filter paper. Braz J Infect Dis. 2010;14(1):24-29.

45. Turbadkar D, Mathur M, Rele M. Seroprevalence of TORCH infection in bad obstetric history. Indian J Med Microbiol. 2003;21(2):108-110.

46. Sahin O, Ziaei A. The role of methotrexate in resolving ocular inflammation after specific therapy for presumed latent syphilitic uveitis and presumed tuberculosis-related uveitis. Retina. 2014;34(7):1451-1459.
Clinical Ophthalmology

\section{Publish your work in this journal}

Clinical Ophthalmology is an international, peer-reviewed journal covering all subspecialties within ophthalmology. Key topics include: Optometry; Visual science; Pharmacology and drug therapy in eye diseases; Basic Sciences; Primary and Secondary eye care; Patient Safety and Quality of Care Improvements. This journal is indexed on Submit your manuscript here: http://www.dovepress.com/clinical-ophthalmology-journal

\section{Dovepress}

PubMed Central and CAS, and is the official journal of The Society of Clinical Ophthalmology (SCO). The manuscript management system is completely online and includes a very quick and fair peer-review system, which is all easy to use. Visit http://www.dovepress.com/ testimonials.php to read real quotes from published authors. 